Reviews

References Cited:

Light, Ivan H. and Edna Bonacich

1988 Immigrant Entrepreneurs: Koreans in Los Angeles 1965-1982. Berkeley: University of California Press

Waldinger, R., Haward Aldrich, Robin Ward, and Associates

1990 Ethnic Entrepreneurs: Immigrant Business in Industrial Societies. Newbury Park: Sage Publications. Ward, Robin and Richard Jenkis, eds.

1984 Ethnic Communities in Business: Strategies for Economic Survival. Cambridge: Cambridge University Press.

\title{
Democracy at Work: A Comparative Sociology of Environmental Regulation in the United Kingdom, France, Germany, and the United States, by Richard Münch with Christian Lahusen, Markus Kurth, Cornelia Borgards, Carsten Stark, and Claudia Jau_ Westport, CT: Praeger (2001), xii, 262 pp.
}

\section{Reviewed by Miranda A. Schreurs, Department of Government and Politics, University of Maryland, College Park, MD 20742}

The comparative study of environmental regulations is enjoying something of a revival because of the dramatic environmental regulatory developments both at the national and international level in the 1990s. This volume contributes a unique perspective to the growing body of literature in comparative environmental studies with its focus on the role of environmental expertise in policy formulation. The authors are interested in explaining why differences in national regulatory styles in the environmental realm persist across the advanced industrialized states. They pick four major countries with democratic, albeit distinct policy making systems for their comparison: the United Kingdom, France, Germany, and the United States. Their comparison focuses on the development of policies to address tropospheric air pollution (as opposed to global warming or stratospheric ozone depletion).

The main argument of the book is that the differences in the environmental regulatory styles of these states can be explained to a considerable degree by the different training of their environmental policy makers, the access of different groups to the policy making process, and the broader policy making culture. Thus, we learn in Markus Kurth's chapter that in the United Kingdom policy making is characterized by a concentration of power in a state that is subject to far fewer restrictions than is found either on the continent or in the United States. Power is regulated not so much by a system of checks and balances as by a culture that values pragmatic compromise and negotiated consensus although differences in policy style were quite strong between the eras of Margaret Thatcher and John Major. This is true in the environmental realm as well where expertise is determined not so much by training as by experience.

Cornelia Borgards argues that in France programs are formulated by a small circle of elites that is dominated by industrial interests but also include the weaker voices of environmental non-governmental organizations (NGOs) and the Environment Ministry. Much policy formulation occurs in informal settings that excludes the public. The "technical professions" are heavily represented in this process and as a result industrial perspectives have the upper hand. Culturally, in France where agricultural interests are strong, nature is viewed as subordinate to humans and it is there for humans to shape. As a result of this constellation of actors, interests, and culture environmental policy is weaker in France relative to other policy areas than in the other three countries examined in this book.

Carsten Stark contends that in Germany air pollution policies tend to be technocratic, legalistic, and focused on the source. Emissions standards are determined by negotiation. Under the law, those who run facilities are obligated to keep up with the "state of technology", but the definition of what the "state" is is defined through negotiation. In Germany, air pollution is corporatist; there is an accommodation between the interests of a few organizations and the state. The public is not well integrated into the permitting process. Instead, there is a 
Reviews

underlying culture among policy makers that portrays the public as being in need of enlightment. In other words, in Germany "a rule by virtue of knowledge" prevails and that knowledge is largely defined by engineers as opposed to, for example, medical experts.

In contrast, with the three European cases explored in this volume, in the United States, suggests Claudia Jau, the policy making process is quite open to the public. In contrast with the consensus-seeking cultures found in Europe, in the United States policy making is characterized by strong competition among interest groups. The public exerts a strong influence on policy as can be seen by the rejection by voters of measures to increase the price of gasoline or expand public transportation networks. Far more than is the case in Europe, there is an antagonistic relationship between the government and industry. Yet, this does not mean that industry has little or no influence over policy formulation. When compared with European countries, the United States stands out for the comparatively strong influence exerted by economists in policy formulation. This explains the embrace of marketbased principles in environmental regulations in the United States. The best known example of this is the 1990 Clean Air Act amendments which introduced a permit trading system for sulfur oxide emissions.

In a long and theoretically-oriented concluding chapter, Richard Münch compares the cultures of democracy explored in the previous four chapters. He labels the United Kingdom as a "representative democracy." Of the four states examined, civil society is strongest in England where policy networks provide opportunities for a wide range of societal interests to express their voice and work towards a harmonization of interests. Policy making relies on informal consultation between the state and interest groups. Compared with other countries where engineers and physical scientists tend to be very influential in the policy making process, in Britain other specialists, including doctors and biologists also hold considerable sway. Thus, in England environment is dealt with in a quite integrative fashion. Yet, there have been changes away from the politics of compromise towards great reliance on market mechanisms as a result of the revolutionary changes to British politics under Margaret Thatcher. Münch concludes his analysis of the British system with comparisons to the philosophical writings of John Locke, John Stuart Mill, and Thomas Hill Green among others.

In contrast, Münch classifies France as an "etatist republican democracy" by which he means a system where the state administration together with a small circle of interests with which the state closely cooperates. Groups must struggle to be recognized by the state since they depend on the state for financial support, and in this system civil society groups are basically a "parasite of the state" (p. 171). Knowledge in environmental policy making is biased towards elite engineers and scientists that determine what is in the best interests of the public. In this system, nature is viewed as an object to be controlled and improved upon. This form of republican democracy has its roots in the writings of Jean-Jacques Rousseau. The idea of a technicoadministrative elite can be compared to the thinking of the Saint-Simonists and examined in the writing of Jacques Ellul.

Germany is labeled a "consensus democracy by rule of law". There is a heavy reliance on committees that are populated by experts. Germany's neocorporatist politics largely defines who the members of these committees will be and makes it hard for new groups to penetrate the policy making process. Germany is frequently defined as a state where the rule of law, rather than a system of pluralism and competition. Experts work together to form a general consensus and integrate this into law. The laws are then interpreted during the implementation process by expert commissions. The roots of this system can be raced to early thinking on enlightened absolutism. In particular, Kant's views that moral principles can only gain validity when made into general law strongly influence German legal and political culture.

Finally, Münch categorizes the United States as a "pluralist competition democracy." The open network of politics in the United States has resulted in a large-scale industry for lobbyists representing various interest groups. In this system, however, not all rights and interests gain equal consideration. Those who are best able to make themselves heard gain the upper hand. In contrast with Germany where science is viewed as a relatively objective institution, in the United States science is a weapon to be used to strengthen one's competitive position. Thus, one finds an unusually large number of scientific research centers in the US that seek to influence the policy process. There is also a belief that the state should not interfere in the lives of citizens but should protect them from harm, and in this system the courts play an unusually big role. This idea of a liberal democracy can be juxtaposed with Rousseau's model of a republican democracy.

This final chapter of the volume raises some intriguing question of what the role of citizens is and should be in environmental policy making. Münch suggests that while the four models explored all have their strengths and weaknesses, the American model of a liberal and pluralist competition democracy may be the best model for the future as Europe moves towards the development of a supra-national state system and globalization processes proceed.

I enjoyed reading this book although the rough English translation of the first couple of chapters was distracting and made it difficult to get into the heart of the material of the book. The systematic comparison of the 
Reviews

role of knowledge and science in policy making and analysis of what this means for the kinds of democracy that prevail in each of these states was really quite intriguing. I particularly liked the effort to examine environmental policy making practices from a political philosophical perspective since this is so rarely done by others in the field. Something that is lacking in the book is the question of how diffusion processes or internationalization (alternatively, globalization) have influenced policy making processes. The book follows a traditional comparativist model that presumes that policy making is largely concluded within the nation state. Yet, in the area of air pollution policy there clearly has been much borrowing of ideas across national borders and thus, there has been an indirect influencing of policy priorities by actors other than those considered by the authors of this book. It would also have been interesting to learn more how the process of integration through the European Union has influenced national policy making styles of the European countries explored in this book. Finally, I was surprised to find so little attention given to the roles played by Green parties and environmental social movements in the individual country chapters. While these movements may not be tightly involved in the actual shaping of concrete laws, they certainly have played an important role in setting the policy agenda.

\section{Land, Wind, and Hard Words: A Story of Navajo Activism, by John Sherry, University of New Mexico Press, 2002.}

\section{Reviewed by Orit Tamir, New Mexico Highlands University.}

John Sherry's Land, Wind, and Hard Words: A Story of Navajo Activism is the story of the founding, activities, and growth of Diné Citizens Against Ruining our Environment (CARE), a Navajo grassroots environmental organization whose initial mission was to protect Navajo reservation forests from the organized assaults of industrial logging. Sherry focuses on the group's ties to Navajo culture. The book is also a tribute to Leroy Jackson and his wife Adella Begaye, the original founders and leaders of CARE - their daily struggles to manage development on the Navajo reservation in a manner that complements the Navajo world view and way of life. It chronicles the mysterious disappearance and death of Leroy Jackson. Sherry provides first hand insight into the lives of CARE Navajo activists, documents the group's experiences with lawyers and environmentalists from the "outside," and describes the media frenzy that follows the death of the group founder.

Sherry follows an introduction of the main Diné CARE actors and the setting for their activities (Chapter One), with a brief history of the Navajo people (Chapter Two). The author than describes the careers of Leroy Jackson and Adella - neither of which had formal education in forest management - as forest activists and founders of Diné CARE.

They knew only that they had to do something to preserve the mountains and forests of the Navajo people (Chapter Three). Sherry's friendship with the couple gave him a unique insight into the daily lives of Navajo environmental activists, the threats to local Navajo communities from industrial logging, and threats to the activists themselves. Diné CARE's first success, the Huefrano case, was achieved through the personal struggles and financial sacrifice of the organization's core activists (Chapter Four). Despite the Huefrano success, CARE's activism and legal wrangles often resulted in local suspicions, but also earned the organization the support and cultural endorsement of Navajo elders (Chapter Five).

Chapter Six addresses the unique Navajo worldview with its close connection between humans, animals, and land that is at the core of Diné CARE philosophy, vis-à-vis the Euro-American tendency to clearly separate the human and non-human worlds. Compounding the problem was the fact that too often contemporary reservation social institutions failed to provide local Navajos with the customary opportunity to voice their concerns (Chapter Six).

Diné CARE's environmental struggles did not focus exclusively on the logging industry. Indeed, the organization expanded its activities to include organization of a spiritual gathering, radio talks, and participation in the Navajo Nation Tribal Council (Chapter Seven). The cost in time and finances of these activities often fell on the shoulders of the organization's core activists. As Diné CARE's exposure grew, so did the financial toll, and the organization had to turn to the cutthroat world of fund raising (Chapter Eight). For the most part Diné CARE 